lymphocytes are actively recruited into the lung including areas outside the treatment field. They suggested that, in addition to postradiation vasculitis, lymphocytes are involved in a hypersensitivity reaction. Certainly there is an increasse in the pulmonary CD4 + helper $T$ lymphocytes and it is possible that selfantigen release occurs with the induction of autoreactive lymphocyte clones. The combination of this reaction with a drug which is also able to cause vasculitis may aid such antigen recognition, creating a "recall" pneumonitis.

We would like to thank Professor Catovsky for permission to report his patient.
1 Newell DR, Gore ME. Toxicity of alkylating agents: clinical characteristics and pharmacokinetic determinants. In: characteristics and pharmacokinetic determinants. In: Powis G, Hacker MP, eds. The toxicity of anticancer

4th edn. New York: Pergamon Press, 1991:44-62.
2 Rosiello RA, Merrill WW. Radiation-induced lung injury.

Clin Chest Med 1990;11:65-71.
Roswitt B, White DC. Severe radiation injuries of the lung. Roswitt B, White DC. Severe radiat
Am ₹ Radiol 1977;129:127-36.

Am f Radiol 1977;129:127-36.
4 Einhorn L, Krausse M, Hornback N, Furnas B. Enhanced pulmonary toxicity with bleomycin and radiotherapy in oa cell lung cancer. Cancer 1976;37:2414-6.

5 Braun SR, doPico GA, Olson CE, Caldwell W. Low-dose radiation pneumonitis. Cancer 1975;35: 1322-4.

6 Trask CW, Joannides T, Harper PG, Tobias JS, Spiro SG, Geddes DM, et al. Radiation-induced lung fibrosis after treatment of small cell carcinoma of the lung with very treatment of small cell carcinoma of the lung with

7 Weiss RB, Posada DS, Penta JS. The nitrosoureas and pulmonary toxicity. Cancer Treat Rev 1981;8:111-25.

8 Helmers RA, Hunninghake GW. BAL and opportunistic infections (editorial). Mayo Clin Proc 1987;62:630-1.

9 Roberts CM, Foulcher E, Zaunders JJ, Bryant DH, Freund $\mathrm{J}$, Cairns $\mathrm{D}$, et al. Radiation pneumonitis: a possible lymphocyte-mediated hypersensitivity reaction. Ann Intern Med 1993;118:696-700

Thorax 1995;50:1118-1119

\section{Management of residual thymic cysts in patients treated for mediastinal Hodgkin's disease}

\author{
A M M El-Sharkawi, B Patel
}

\begin{abstract}
The pathogenesis of residual thymic cysts after treatment for mediastinal Hodgkin's disease is uncertain. Their presence after adequate treatment often presents the oncologist and the thoracic surgeon with a therapeutic dilemma. Two patients with residual thymic cysts after curative treatment for mediastinal Hodgkin's disease are described and the management discussed.

(Thorax 1995;50:1118-1119)
\end{abstract}

Keywords: Hodgkin's disease, thymic cysts, radiotherapy, chemotherapy.

Thymic cysts are occasionally found after the completion of planned treatment for patients with mediastinal Hodgkin's disease. Their presence on chest radiographs or computed tomographic (CT) scans may indicate either residual or recurrent disease or a benign lesion.

Surgical excision followed by histological examination is the most reliable method of evaluating the possibility of viable tumour within the residual thymic cysts, but this may be dangerous and unnecessary. Needle biopsy, although safer, can produce false negative results. Further chemotherapy and/or radiotherapy may be given to these residual thymic cysts without pathological confirmation, which could be unnecessarily harmful and may even lead to death in patients with no viable lymphoma cells.

We report two patients who received no supplementary treatment for residual thymic cysts and who remain alive and well 2-6 years after their initial treatment.

\section{Case reports}

CASE 1

A 28 year old man presented with enlargement of the right cervical lymph nodes. A biopsy specimen demonstrated nodular sclerotic Hodgkin's disease. The chest radiograph showed mediastinal widening and a computed tomographic (CT) scan of the chest showed a thymic cyst in addition to the mediastinal lymphomatous masses (fig 1A).

The patient was treated with three courses of chemotherapy (adriamycin, bleomycin, vinblastine and DTIC) followed by a radical course of radiotherapy to the mediastinum and cervical and axillary regions. The follow up CT scan approximately nine months after commencing treatment showed complete resolution of the lymphomatous masses in the neck and the mediastinum but no change in the cystic mass. Annual CT scans were performed and the CT scans taken three years and six years after treatment serve to confirm that the patient remains in complete remission (fig 1B).

CASE 2

A 26 year old woman presented with left supraclavicular lymphadenopathy. A biopsy specimen showed nodular sclerotic Hodgkin's disease. A chest radiograph showed mediastinal widening and a CT scan confirmed the mediastinal lymphadenopathy and also a thymic cyst.

The patient was given six courses of chemotherapy consisting of epirubicin, bleomycin, vinblastine, and prednisolone. The thymic cyst at initial presentation was $7 \times 4 \mathrm{~cm} ; 3-6$ monthly follow up CT scans showed considerable reduction in size to $2.3 \times 1.2 \mathrm{~cm} 10$ months later. The cyst has remained the same size on the two year follow up CT scan. 


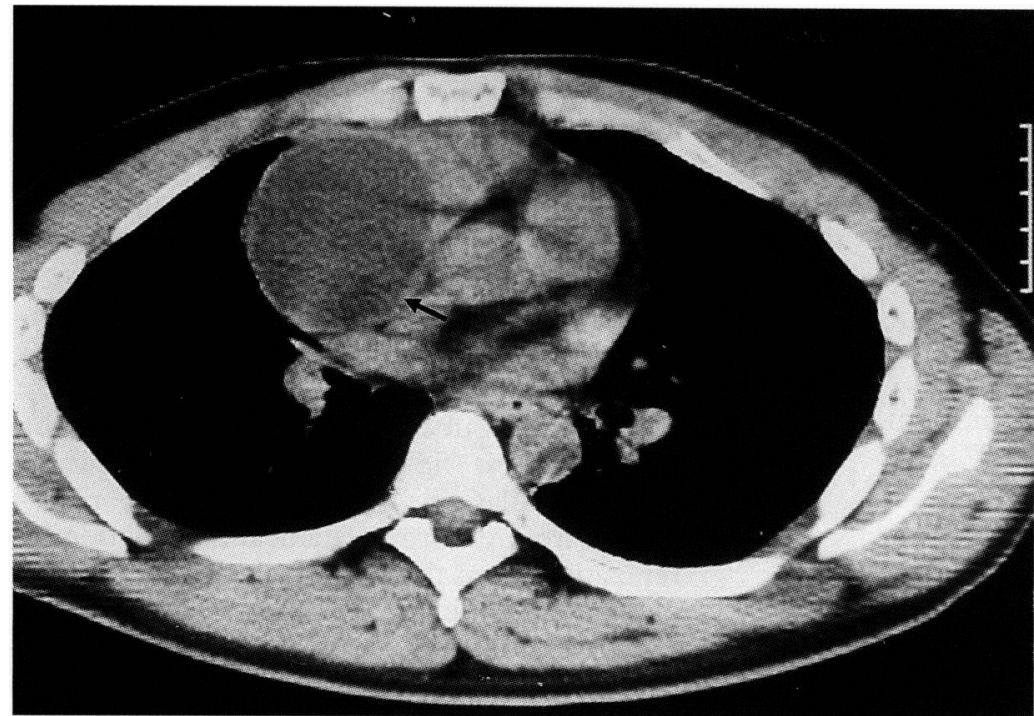

A

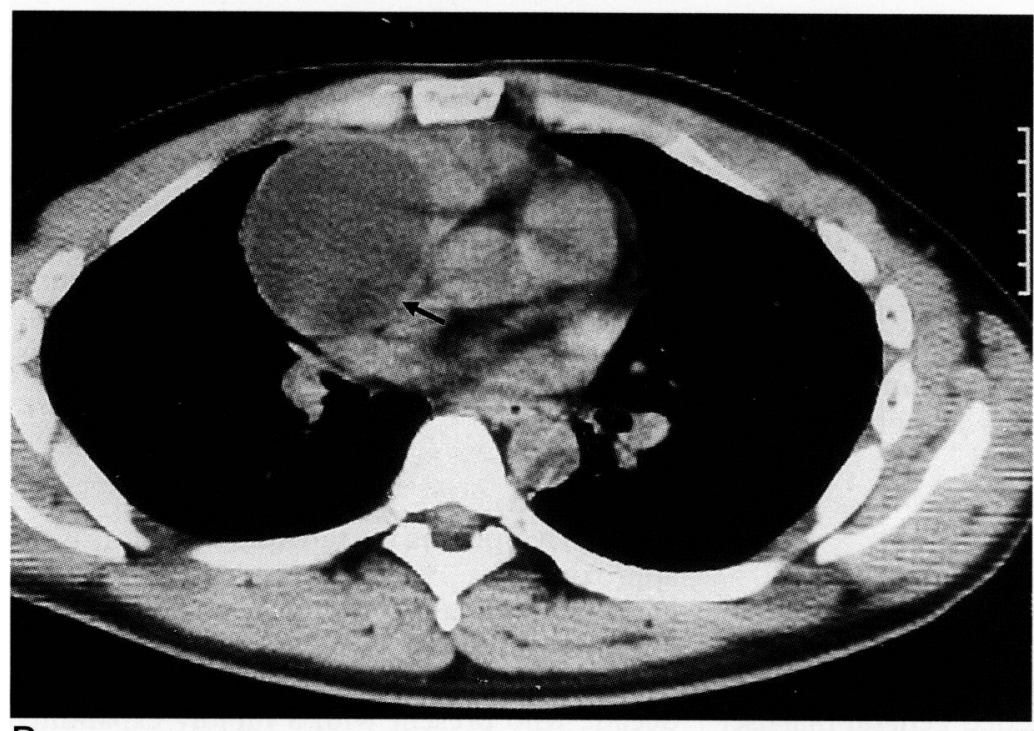

B

Figure 1 (A) CT scan at level of carina before treatment showing thymic cyst (arrow) in addition to mediastinal lymphomatous masses. (B) CT scan at the level of the carina three and six years after treatment showing resolution of the lymphomatous masses and persistence of the cyst. troversial and two conflicting views exist. The first assumes these cysts to be treatment related ${ }^{23}$ and the second suggests that they are due to thymic infiltration by lymphomatous tissues, either on presentation or at recurrence. ${ }^{45}$

In the two cases described, pretreatment CT scans showed large areas of low attenuation within the mediastinal lymphomatous masses which suggested that such cysts were secondary to the thymic involvement by Hodgkin's disease. The CT scans taken after treatment, however, showed persistence of these cystic lesions despite regression of the lymphomatous masses. In the first case the thymic cyst remained static for six years, and in the second it was resolving spontaneously over time.

The natural history of thymic cysts following treatment in mediastinal Hodgkin's disease is not known. However, persistent relapse-free survival can usually be achieved only after complete resolution of all viable tumour. The management of residual thymic cysts seems uncertain, especially when the initial mediastinal Hodgkin's disease responds well. For such thymic cysts, three options are available: further pathological confirmation, further treatment, or observation. The two patients reported here are alive and well, suggesting that these cysts did not contain a malignant component. Baron et $a l^{6}$ recommended that supplementary treatment should not be given for residual thymic cysts without pathological confirmation after one of their patients died of complications which were probably related to excessive treatment.

In conclusion, careful observation with regular follow up CT scans without additional treatment seems to be the management of choice for residual thymic cysts of mediastinal Hodgkin's disease.

1 Ringertz N, Lidhalm SO. Mediastinal tumour and cysts. $\mathcal{F}$ Thorac Surg 1956;31:458-87.

2 Katz M, Piekarski JD, Bayle-Weisgerber Ch, Laval-Jeantet M, Teillet F. Masses mediastinales residulles post-radiotherapsigues au cours de la maladie de Hodgkin. Ann Radio (Paris) 1977;20:667-72.

3 Scully RE, Mark EJ, McNeely BU. Case record of the Massachusetts General Hospital: case 47. $N$ Engl $\mathcal{f} \mathrm{Med}$ 1982;307:1391-7.

\section{Discussion}

Thymic cysts are very rare. In a 10 year review of all published cases of mediastinal tumours and cysts only one case of thymic cyst was reported. ${ }^{1}$ However, thymic cysts are known to occur occasionally in patients with mediastinal Hodgkin's disease. Their histogenesis is con- 